\title{
A Guide to Psychiatric Textbooks for Medical Students
}

\author{
John Dunn, Registrar in Psychiatry, St Thomas' Hospital, London SEl
}

At an important interview, a candidate was asked about his experience in teaching medical students. He replied with an enthusiastic and detailed account of his seemingly extensive experience in this field. However, when asked to name one psychiatric textbook suitable for medical students there followed a fumbling and paradoxical silence. When asked the same question, although able to name a small number of such books, embarrassingly I had to admit that as a student I had never possessed any one of them. I subsequently put the question to some of my colleagues and was reassured to find that my own omission was commonly shared.

When faced with recommending a textbook for medical students the difficulty lies in deciding which criteria, in addition to the price, should be considered. I suggest the three areas that should be reviewed:

Firstly, and most importantly, is the quality of the chapter on psychopathology: this, after all, is the bedrock of psychiatry, and knowledge of this should be regarded as the minimum standard to be attained by all medical students. This subject has the added advantage of being at the beginning of most psychiatric textbooks and therefore the chapter most likely to be read. If the primacy and novelty effects so often described by psychologists are to be believed, it is also the one most likely to be remembered.

The second criterion concerns the section on drug treatments, though psychodynamic psychiatrists might disagree with this point. However, it is the use of pharmacological agents in the treatment of mental illnesses that give psychiatry justification for remaining under the umbrella of medicine, rather than sociology, psychology or other disciplines. The effects and side-effects of, and the indications and contra-indications for, psychotropic drugs are an essential part of the medical knowledge.

Finally, the third criterion I suggest is the attention and space given in the text to the use of community and social approaches in the management and after care of mentally ill people. Admitting patients to hospital for treatment, although frequently necessary, is not always appropriate and may reflect a lack of imagination as well as a lack of suitable alternatives. These facilities and provisions should be well described, as only by being aware of their existence can we increase our therapeutic armoury for the benefit of our patients.

It is not my proposal that psychiatry should be learnt from a textbook. Knowledge of the printed word is no substitute for experience, but it is an important adjunct. With the above criteria in mind I shall review six psychiatric textbooks that are marketed for medical students. My intention is to provide only a guide to the quality of some of the books available and not an exhaustive account of all such books that can be found.
(1) Key to Psychiatry. A Textbook for Students. M. J. Sainsbury. Chichester: John Wiley \& Sons. 1980. £11.95.

This book is written with nursing students in mind but it is eminently suitable for medical students. The author, a psychiatrist, works at the Institute of Psychiatry in New South Wales. The whole approach of the book is strikingly different from many of those which are homegrown; psychiatry in practice is the theme, making it a very readable text. The chapter on psychopathology is detailed and methodically presented. Drug treatments are well covered and as well as discussing the indications for use, side effects and suggested doses, the author makes several interesting points, for example, chlorpromazine suppositories in $100 \mathrm{mg}$ doses are "available but rarely used". Community care is detailed and is emphasised throughout the book. Other worthy chapters include: "The nurse as a person" and "The hospital as a therapeutic community". Being an Australian book, the Mental Health Act 1983 is omitted, but this is a small price to pay for the many outstanding features is possesses.

(2) Psychiatry. Sir William Trethowan and A. C. P. Sims. London: Baillière Tindall (HBJ) 5th Edition. 1983. £7.50.

Considered by many psychiatrists as the standard student text, this view is not necessarily shared by an equal proportion of medical students. It is a comprehensive book and very reasonably priced. Psychopathology is described in great detail, perhaps too much detail for the student. The treatments section is divided into three parts: social, psychological and physical. Drug treatments are systematically reviewed, although actual doses are not mentioned. The Mental Health Act 1983 is outlined in a realistic manner, reflecting its use by psychiatrists in every day practice. The community approach is apparent throughout under such subheadings as: "The role of the social worker" and "voluntary associations" (meaning organisations). This is an excellent book, but perhaps of more interest to the aspiring psychiatrist rather than the future thoracic surgeon.

(3) Psychiatry for Students. D. Stafford-Clark and A. C. Smith. London: George Allen \& Unwin. 6th Edition. 1983. f8.95.

The format of this book differs from the previous two, in so far as there are no separate chapters on either psychopathology or drug treatments. Both these areas are fairly well covered in the subsequent chapters on the individual psychiatric syndromes. Community psychiatry is not mentioned in depth, although the "Management of chronic schizophrenia in the community" is discussed briefly. The almost token comment that mild cases (of acute 
schizophrenia) can be managed in a day hospital seemed to me to suggest that the authors did not have much confidence in this approach.

This book is less detailed than the two above and in the brevity and economy stakes has little more to offer than the short textbook mentioned below.

(4) Lecture Notes in Psychiatry. J. Willis. Oxford: Blackwell Scientific Publications. 6th Edition. 1984. £6.50.

The Lecture Notes series is generally much esteemed by medical students for their consistent brevity and portability, but they are often disliked by the specialist who sees his or her speciality boiled down to an insulted and cachexic carcass.

The Lecture Notes in Psychiatry give a very brief account of psychopathology which is little more than a list of signs and symptoms with explanatory definitions. Physical treatments are presented concisely and drug doses are suggested. Despite the chapter subheading "The Mental Health Amendment Bill 1983" the text itself describes the 1959 Act. There is no separate chapter on community care but such an approach is discussed in the treatments sections of the various psychiatric syndromes.

Intended as "Notes" and not as a standard reference this book achieves its objective. However, there is a temptation amongst students to use such books as a sole text, in which case I should be less than enthusiastic in recommending it.

(5) Handbook of Psychiatry. R. Priest and G. Woolfson. London: Heinemann. 8th Edition. 1986. £7.95.

The chapter on psychopathology is extremely brief, although further information is given in the subsequent chapters on psychiatric syndromes. Drug treatments are well covered and well laid out. Community care is briefly outlined in the chapter entitled "Organisation of Psychiatric Care", but otherwise it is not greatly emphasised. On the practical side, nursing care is discussed in relation to the management of the patient with schizophrenia, which is highly commendable as these important professionals are often ignored in many "heavier" psychiatric textbooks.

(6) Notes on Psychiatry. I. M. Ingram, G. C. Timbury and R. M. Mowbray. Edinburgh: Churchill Livingstone. 6th Edition. 1985. £5.25.

This book is certainly the cheapest and, along with Lecture Notes, the briefest, so much so that one wonders why it took three authors to write it. Psychopathology is reduced to a four page review of "Common Abnormalities". The chapter on psychopharmacology is concise and well set out. Community care is not considered separately and in the section on schizophrenia its significance is relegated to one short paragraph. Rehabilitation fares better and is outlined in a separate chapter.

Like Lecture Notes, this volume is not intended as a reference book. Nevertheless, since the average student is unlikely to purchase two psychiatric textbooks, it is easy to see how this could be used as one, which cannot be recommended.

To see the whole field of psychiatry reduced to a 160 page volume with frequent headings and well spaced print inevitably represents psychiatry as a very limited subject which has little to say for itself. This diminishes the credibility of psychiatry and the self-esteem of psychiatrists. Psychiatry is a speciality, the importance of which is far greater than its popularity within the medical profession as a whole.

In the final analysis it is up to the student to decide which, if any, textbook he or she would like to read and learn from. When time and money are used as the criteria to judge a book by, brevity and cheapness take on disproportionate importance. Better informed medical students might become better informed doctors, possessing a greater insight and understanding of psychiatric phenomena which are relevant to all branches of medicine. An introduction to psychiatry through a textbook is not offered as a panacea for the uninformed, but it is a step in the right direction.

\section{Psychiatric Practice in the Developing World}

The Department of Psychiatry, University of Manchester, will be running a one-week course on 'Psychiatric Practice in the Developing World' from 4-8 January 1988. The course will concentrate on aspects of service planning, administration, public education, epidemiology, and training in areas of psychiatry of particular importance in a developing country. The course will not systematically cover research methodology but there will be sessions on data analysis and the presentation of data in lectures and publications.
The cost of the course will be $£ 40$ per day or $£ 190$ for the whole week and will include lunch and other refreshments. Accommodation can be arranged in the University Halls of Residence at a further cost of $£ 11.50$ per night.

Further information and application forms can be obtained from Linda Hollos, Administrator, Department of Psychiatry, University Hospital of South Manchester, West Didsbury, Manchester M20 8LR.

\section{First Annual Lecture on 'Research in Psychoanalysis'}

The Research Committee of the British Psycho-Analytical Society announces the above lecture to be given by Professor Robert S. Wallerstein, President of the International Psychoanalytical Association, on 4 November 1987 at 8.30 p.m. at the Institute of Psycho-Analysis, Mansfield House, 63 New Cavendish Street, London WIM 7RD (telephone 01580 4952). Admission by ticket only from the Scientific Executive Officer at the above address. 